\title{
Village Morphology and the Construction of Place Identity in the Aihui Area along the Heilongjiang River, China
}

\author{
Dong $\mathrm{Wei}^{1}$, Yang $\mathrm{Yani}^{1}$, and Dong $\mathrm{Yu}^{1}$ \\ ${ }^{1}$ Harbin Institute of Technology
}

May 3, 2021

\begin{abstract}
Place identity is the emotional connection between people and a place. It is significant for local development and people's satisfaction and happiness in where they reside. The physical environment is one of the most important factors affecting people's emotions toward a place. In order to clarify the theoretical analytical framework of the process from village space morphology to place identity, this study takes the area of Aihui along the Heilongjiang River, China, as an example. The research was conducted regarding two aspects: First, we analyzed the space morphology of the villages in the Aihui district and interpreted their locality. On this basis, we conducted a survey of villagers' subjective perceptions of the village space and their place identity through in-depth interviews. From the collected interview texts, we extracted, verified, and analyzed the role of morphological constituents in the construction of place identity. Finally, a comprehensive framework was established. The features of space morphology are the projections of locality in physical space. People use morphological constituents to construct an image of the village and scenes of local life; morphological constituents with local characteristics can help enhance people's place identity.
\end{abstract}

\section{Hosted file}

Village_Morphology_and_the_Construction_of_Place_Identity_in_the_Aihui_Area_along_the_Heilongjiang_Rive available at https://authorea.com/users/411601/articles/520577-village-morphology-and-theconstruction-of-place-identity-in-the-aihui-area-along-the-heilongjiang-river-china 